\title{
IMPLEMENTING ELECTRONIC PORTFOLIOS THROUGH SOCIAL MEDIA PLATFORMS: STEPS AND STUDENT PERCEPTIONS
}

\author{
David W. Denton \\ David Wicks \\ Seattle Pacific University
}

\begin{abstract}
Over the last two decades, students and teachers, across educational levels and disciplines, have been subject to a variety of school reform efforts. Nevertheless, some instructional practices, such as portfolio assessment, persist and grow in popularity even in the midst of changing educational reform goals and shifting priorities. Teacher education programs have used paper-based portfolios for more than three decades. Recently, institutions have migrated to electronic portfolios since these provide several advantages. Early models of these systems required special technical skills, hardware, or fee-based contracts with service providers. The newest iteration of portfolio platforms are based on social media applications, which are easy to use, free, and customizable. However, the accelerated adoption of social media applications as repositories for student portfolio content has produced several gaps in the literature. Three of these include steps for implementing electronic portfolios in social media platforms, instructional methods for soliciting quality entries from students through questions and prompts, and student perceptions about using social media as a repository for electronic portfolio content. Results from a case study identifying student perceptions of combining social media and electronic portfolios are examined. Future lines of inquiry are discussed.
\end{abstract}

\section{KEYWORDS}

Blog, case study, education reform, electronic portfolio, social media, teacher education

\section{INTRODUCTION}

In 2007, the former United States Secretary of Education, Margaret Spellings, convened a commission on the future of higher education [1]. The commission suggested several changes for improving colleges and universities. While most of the recommendations have gone nowhere, some have coincided with actual reforms. Although inconsistently adopted by institutions, two changes of this type include posting performance-related data to institution websites, and using standardized tests to allow for comparisons between colleges on student performance measures [2].

Accountability, transparency, and continuous improvement are the ideas reformers call upon to rationalize these initiatives. Nevertheless, teachers and administrators in K-12 settings have been contending with similar attempts at educational improvement since the 1990s, under the auspices of America 2000, Goals 2000 and No Child Left Behind legislation [3-4] Similarly, teacher education programs have long dealt with oversight measures, both from state level education boards and professional accrediting organizations.

An important objective woven into all of these supervision-related strategies, regardless of the context within which they are deployed, is to improve student achievement and produce competitive workers for life in a global marketplace. In the case of higher education, at least according to the Spellings Commission, this goal is reached by increasing student test scores, while reducing costs [1]. Likewise, for 
those teaching and learning in K-12 settings, it means improving test scores through elaborate systems of itemized standards, yearly assessments, and published achievement results, with sanctions for failure.

Like other levels and branches of education, teacher training programs have not escaped outcome-based reform. Along with K-12 educators, faculty working in teacher education programs are required to integrate published lists of professional knowledge and skills, derived from professional organizations, such as Interstate Teacher Assessment and Support Consortium, and more often, from State legal code. These lists outline what new teachers are supposed to "know and be able to do." Like other systems, these standards are paired with assessments, which measure a variety of outcomes, such as dispositions, content knowledge, pedagogical knowledge, and professional growth. The battery of assessments that teacher candidates and faculty contend with is increasing. The most recent example is Teacher Performance Assessment, which has been adopted by many states in order to improve the likelihood of winning Race to the Top Federal grant money [5].

Over the last 20 years, educators at every level have experienced changes in education, such as those exemplified by TPA. These efforts are summarized as addition, subtraction, and revision of standards and assessments, and more generally, more complex oversight policies [6] Nevertheless, some teaching and learning activities have persisted across these decades because of their perceived usefulness and empirically proven effectiveness [7-9]. Portfolio assessment, which is a popular method for showing preservice teacher competence on professional knowledge and skills, is one of these [10].

Since the $80 \mathrm{~s}$, professional teaching portfolios have been part of the teacher education curriculum [11]. Although there are a number of definitions of portfolio, one of the most widely cited is Shulman's, who summarized it as a "structured documentary history of a (carefully selected) set of coached or mentored accomplishments substantiated by samples of student work and fully realized... through reflective writing, deliberation, and serious conversation" [p. 23, 12]. Two of the qualities that make portfolio assessment popular as a facet of teacher education include the ability to chronicle changes in student knowledge and skills and the belief that reflective writing shapes future teaching behavior [13-14]. However, portfolios also serve a less idealistic, if not equally important, requirement. They are used to show competence on professional teaching standards, satisfying both national accrediting groups, such as National Council for Accreditation of Teacher Education, and state level licensing agencies [15].

The first portfolio models in teacher education were paper-based, typically organized in three-ring binders [16-17]. More recently, many schools of education have migrated from paper to electronic methods for storing and presenting portfolios [17]. Electronic formats vary, as do the names with which they are identified, including blog portfolios, bportfolios, digital portfolios, electronic portfolios, eportfolios, efolios, or web-folios [11] [18].

According to Abrami and Barrett, an electronic portfolio is "a digital container capable of storing visual and auditory content including text, images, video and sound" [p. 2, 19]. Along with these functions, electronic portfolios have several advantages in comparison to paper portfolios, such as enabling users to search, retrieve, change, link, and organize narratives and artifacts [20]. Likewise, Lumpe, Wicks, and Williams identified contemporary advantages of electronic portfolios, many of which are particular to social media platforms, including tagging entries for organization, data mashup integration, and rich site summary (RSS) notification to promote peer assessment [18]. One of the most significant differences is that social media-based portfolios are readily accessible to users, peers, instructors, and public spectators.

Gibson and Barrett distinguished between two types of electronic portfolio platforms, including generic tools and customized systems [21]. According to these authors, generic tools include "word processing, HTML editors, multimedia authoring tools, portable document format (PDF), and other commonly used productivity software" [p. 559, 21]. Alternatively, customizable systems are identified by the use of "servers, programming, and databases" [p. 559, 21].

However, Gibson and Barrett [21] used these categories to describe electronic portfolio platforms several years ago. Since this time, a host of new online applications have emerged, which require even fewer technical skills and less specialized hardware in comparison to what Gibson and Barrett suggested less 
Implementing Electronic Portfolios Through Social Media Platforms: Steps and Student Perceptions

than a decade ago. Most of these platforms are divisible into one of three categories, including add-on, independent, and social media [22]. Add-on portfolios are extensions of existing learning management systems, such as Mahara with Moodle, Angel e-portfolio with Angel, and ePortfolio.org with Blackboard. Alternatively, independent systems do not require a preexisting learning management system, but function without additional software or services. Examples of independent systems include Chalk and Wire, Live Text, and Task Stream. Social media portfolio tools include Web 2.0 applications that allow users to store and present content online. Examples include WordPress.com, Edublogs, Blogger.com, Wikispaces.com, Weebly.com, and Google Sites.

An important commonality between these platforms is that they are accessed through a web browser. Another is that they employ digital dashboards for monitoring and adding features and content. Some systems require on-site servers and storage, whereas others do not. Each platform involves its own set of complexities, depending on its design. As such, each requires users to learn and practice adding entries and adjusting display options. However, unlike electronic portfolio systems of the past, users do not need specialized skills or hardware [23]. Moreover, ease of use is sure to increase as programmers improve dashboard interfaces. Likewise, many students are already familiar with internet page authoring through applications like My Space, and Facebook.

The most significant difference between these platforms is cost, framework, and open or walled-garden access. The software for Mahara is free, but requires a server or web hosting with domain name. Alternatively, ePortfolio.org costs between $\$ 10$ and $\$ 30$ per user per year. Chalk and Wire, Live Text and Task Stream cost between $\$ 20$ and \$28 per user per year. Alternatively, social media applications are free, but can include file size upload limitations or other restrictions. For example, WordPress.com will display advertisements on blogs that receive multiple visitors, although users can eliminate this feature by paying $\$ 30$ per year.

Add-on and independent platforms provide program administrators with customizable templates for uploading and presenting content. However, in order to improve production efficiency, these templates represent a limited number of structures and options. The most prominent features include text boxes, drop-down questions, and file attachment buttons. Users construct their portfolios by uploading assignments into predefined spaces and completing reflective response questions for each upload. Add-on and independent platforms also enable users to submit the entire portfolio, or select portions, for assessment to a designated person. Additional options include assessment features, such as integrated rubrics and grade book [24]. Social media applications do not provide users with a framework, but they can be customized using general editing techniques, such as adding pages, widget tools, and a theme.

Another difference between platforms is support. For example, subscribers to Chalk and Wire, LiveText, and Task Stream have access to various portfolio-specific support materials, such as online orientation, on-site training, webcasts, email correspondence, and custom guides. Users of social media platforms can also access support materials. However, these are limited to general forums and instructional documents.

Vendor-based portfolio designers generally use a walled-garden approach, which means that access to portfolio content is dependent on assigned security clearance, similar to the kind of access instructors and students encounter with learning management systems. Alternatively, social media platforms are public, unless the user restricts viewing by requiring login and password access.

\section{LITERATURE RELATING TO SOCIAL MEDIA PORTFOLIO PLATFORMS}

Predictably, there is a dearth of peer reviewed research pertaining to the use of social media portfolio platforms because of the pace with which these technologies are being implemented in higher-education. For example, searching the Education Resources Information Center database using the keywords electronic portfolio and blog produced six results. Likewise, searching for the keyword social media and portfolio produced one result. 
Implementing Electronic Portfolios Through Social Media Platforms: Steps and Student Perceptions

Among these, Chuang investigated the effects of having 31 education students use Blogger and WordPress to record reflections and post artifacts for 10 months [23]. As part of this study, Chuang discussed advantages and disadvantages of both blog platforms, such as ease of use and storage space limitations [23]. However, the primary focus of this study presented an analysis of students' portfolio content.

Two additional studies, one by Klages and Clark, and another by Hsu and Wang, examined the effects of integrating blogs to improve basic writing and reading skills with undergraduate students [25-26]. Both studies, which involved a combination of qualitative and quantitative measures, reported notable but inconclusive results.

Bonk and Zhang proposed an instructional model for teaching students in online courses [27]. The authors emphasized reflective activities as a component of this model, along with suggesting blogs and electronic portfolios as a suitable method for containing and presenting reflective writing. Similarly, Sawmiller delineated the uses and advantages of blogging as an instructional practice for enhancing collaboration and achievement with secondary science students [28]. This article also devoted a small portion of text to describing implementation, such as considering the Family Educational Rights and Privacy Act when posting electronic portfolio content, such as student images, online [29].

In another summary, Waters surveyed the development of various electronic portfolio platforms, along with providing an analysis of strengths and weakness of several, such as Epislen, Desire2Learn, and Mahara [22].

In a significant departure from the studies and summaries already identified, $\mathrm{Kim}, \mathrm{Ng}$, and Lim described a search application under development, which is capable of presenting data stored on various cloud services, such as YouTube, Facebook, and Flickr, through a semantic web interface [30]. The authors suggested that the application, titled Private-Public data index system, could be used for assembling electronic portfolio content from a user's cloud-based data.

Collectively, these studies add to the growing body of literature on electronic portfolios in the areas of content analysis and future trends. However, they do not address aforementioned gaps in the literature.

\section{STEPS FOR IMPLEMENTING ELECTRONIC PORTFOLIOS IN SOCIAL MEDIA PLATFORMS}

Although implementing electronic portfolios using social media platforms will vary depending on individual need and institutional requirements, there are some common steps. The first of these is defining the purpose and scope of the portfolio. Barrett summarized purpose and scope of electronic portfolio keeping around three activities, 1) including promoting student reflection on evidence of learning, 2) showcasing accomplishments, and 3) documenting competency on accountability standards [31]. For example, electronic portfolios in teacher education programs are used for documenting preservice teacher knowledge and skills [32-33]. Alternatively, they are also used for securing institutional accreditation [15]. If, as is the case in teacher training, an electronic portfolio is used for multiple purposes, then communicating these to users during setup justifies the expenditure of time and resources. Determining the range of time for which the portfolio is used is another factor influencing setup. Implementing an electronic portfolio for a single class may warrant a rudimentary structure and interface, such as using only the blog feature of WordPress to add text, without requiring the use of additional options, such as pages, widgets, and multimedia attachments. Alternatively, implementing an electronic portfolio across multiple years requires investing time to create a model, disseminate instructional materials, and establish methods for scoring. Unlike the single-class project approach, long-term use of portfolios for licensing and credentialing requirements means securing participation from multiple instructors and program staff. In addition, issues relating to when and how students add content to their portfolios, along with implementing commensurate assessment procedures, involves system-wide planning and administrative support.

Although there are a number of social media platforms which serve as electronic portfolio containers, the 
Implementing Electronic Portfolios Through Social Media Platforms: Steps and Student Perceptions

most common include Wordpress, Blogger, Google Sites, and Weebly. The interface for each of these is different, even though they require similar levels of web editing skill. However, Google Sites and Weebly enable users to login using Google Drive and Facebook account information, respectively. On the one hand, this simplifies account setup and login, but it also networks multiple social media applications, which students may perceive as undesirable.

Creating and testing temporary trial portfolios is an effective way for instructors or administrators to decide on a particular platform. Criterion useful for making comparisons between platforms include the amount of personal information required for creating an account, simplicity in steps for adding and accessing content, and whether the platform displays ads. Trial blogs and websites can be abandoned without consequence if, upon experimentation, the platform is determined to be insufficient.

For example, in a pilot study conducted by one of the authors, two intact groups of students created portfolios using different Web 2.0 tools. The first group used Google Sites to create and edit narratives, documenting how they demonstrated competence on professional standards. Google Sites served as a website, specifically a wiki environment where students could easily edit pages as they acquired new evidence to document. Faculty found the portfolios easy to navigate, but found assessing activity or growth challenging, as it was not clear when or where content changes had been made. The second group used WordPress.com to reflect on learning and document how standards were met. Students wrote blog posts to reflect on their learning. They used the category feature in WordPress to identify which standards where addressed in each reflection. Finally, they used the Pages features to write meta-reflections, which served as narratives for demonstrating competency on each standard. Faculty found the sites both easy to navigate and easy to track growth. Both groups reported positive experiences. Nevertheless, the blogging features of WordPress enabled students to engage with Barrett's suggested purpose and scope of electronic portfolio keeping more readily in comparison to Google Sites.

Once a platform has been selected, then a model is constructed for replication by students (model shown at http://sputeacher.wordpress.com). An effective model shows the general structure of the portfolio, such as number of pages and location of links, along with type and location of add-on features, such an archive and tag cloud. The characteristics of superior portfolio entries, both with regard to format and content, are also shown through example postings. The model builder may add an auxiliary page to present instructions and support materials.

As part of the setup process, students require instruction regarding appropriate use of their portfolio. One authoritative source for this is the International Society for Technology in Education, which defines expectations for demonstrating digital citizenship [34]. Students practicing digital citizenship use technology in 1) safe, legal, and responsible ways; 2) exhibit a positive attitude toward technology for collaboration, learning and productivity; 3 ) demonstrate lifelong learning in the area of technology; and 4) promote values underlying use of technology in education [34]. Another source, relating to students and instructors, is the Family Educational Rights and Privacy Act [29]. One statute in FERPA prohibits schools from disclosing personally identifiable information derived from education records. An instructor who posts grades or evaluative marks to a student's online portfolio risks violating this requirement. However, FERPA does not prohibit students from choosing to release personal information to third parties, so instructors who request that students create personal accounts to access social media for academic purposes is permissible. Moreover, none of the language in FERPA prohibits students from posting comments on the portfolio of a peer. Similarly, FERPA does not prohibit the disclosure of directory information so that instructors or administrators may catalog the URL location of students' electronic portfolios and display these online.

Standards and regulations set by ISTE and FERPA promote appropriate use of social media portfolios. Nevertheless, there are additional precautions to consider. For example, students should be discouraged from showing personal information, such as phone number, birth date, and address. Similarly, students completing internships increase the possibility of an unfavorable experience by revealing the identities of participating institutions and specific persons, such as mentors. This is especially true when portfolio entries contain descriptions that are overly critical, biased, or error prone. If the portfolio shows these 
kinds of deficiencies then it becomes a liability, both in terms of displaying academic competency and securing future employment opportunities. Students using portfolios constructed in social media containers are more vulnerable to this problem, since content is open for public viewing.

\section{INSTRUCTIONAL PRACTICES FOR PROMPTING QUALITY PORTFOLIO ENTRIES}

Training and instruction regarding these issues improves the likelihood that students fill their portfolios with information that fulfills the purpose of the portfolio. Nevertheless, eliciting quality entries from students requires the same level of attention and effort as other learning activities.

One of the factors influencing the quality of portfolio entries is prompting [35]. Initially, when students are asked to reflect on their learning or experiences, they tend to use description, opinion, and personal anecdote [16] [36]. Although these writing formats are useful, they do not enable the same level of reflection and self-assessment as characterized by analytical or expository writing [11-12].

There are a number of methods for prompting writing that assists students in contributing quality entries to their portfolios. However, writing prompts, either as questions or statements, are among the simplest to create and most effective to use [37-38]. For example, students summarize assigned text reading passages and elaborate on the implications of the subject matter for practice. Alternatively, students compare and contrast competing models, theories, or ideas, analyzing the strengths and weaknesses of each.

Presenting an item to students for analysis is another prompting method. For example, in the case of teacher education, one type of item is a work sample. Portfolio users can analyze the sample as evidence of student learning, including progress toward the learning objective, gaps in understanding, and subsequent steps of instruction. Case analysis is a variation of this method, which substitutes a situation or scenario for analysis instead of an item. Question strands for conducting case analyses include 1) identifying problems, 2) proposing solutions, 3) listing advantages and disadvantages of recommendations, and 4) evaluating outcomes. An asset related to this activity is that users can include items and case scenarios as part of the analysis, uploading them with the entry as an attachment, or inserting them as images, for reference.

When students use their portfolios for evaluating their own learning, they are often required to include artifacts as evidence or proof of achievement. As part of this process, students compare their accomplishments to a set of professional or program standards along with an artifact for evidentiary support. Artifacts include assignments from previous coursework, images showing participation in an event, narratives describing internship experiences, and the like. Converting artifacts to portable document format (PDF) or screenshot images simplifies access for viewers. Similar to previous methods, structured questions or prompts facilitate quality writing for this type of entry, such as 1) description of the artifact, 2) description of how the artifact shows evidence of meeting related professional standards, 3 ) assessment of competence gained from the experience, 4) analysis of impact on professional effectiveness, and 5) prediction of future training for improvement [36].

A final method, descriptively named blog buddies, engages students through a system of peer assessment. Blog buddies are assigned pairs of students who read and comment on blog entries over the course of a class. Advantages of this method include accountability for meeting submission deadlines, guarantee that posts are read, and reduction in the amount of entries an instructor is responsible for assessing. One facet of blog buddies is that students receive credit for their own post after they have written a comment on their buddy's post.

\section{V.STUDENT PERCEPTIONS OF COMBINING SOCIAL MEDIA AND ELECTRONIC PORTFOLIOS}

Another important issue, along with implementation and prompting is student perceptions regarding the integration of social media with learning. The reason most people use social media is to share personal and professional activities, and to monitor the activities of friends, colleagues and family. The primary 
Implementing Electronic Portfolios Through Social Media Platforms: Steps and Student Perceptions

use of applications like Facebook, Twitter, Pinterest, and Google+ is to promote these types of online interactions. Presenting professional qualifications and locating prospective employers is another prominent use of social media, as shown through sites such as Linkedin. Blogs stimulate another set of presumptions among students. Often, blogs are defined as online diaries, filled with personal opinions and descriptions of life experiences. Fewer students see connections between social media, such as blogs, for educational purposes. Nevertheless, Couros has suggested a model for how teachers integrate social media and traditional resources to create personal learning networks [39]. Similarly, the National Education Technology Plan encourages teachers to use social media to connect with other teachers and share resources [40].

Evidence that students possess positive and negative perceptions about combining social media with electronic portfolios is shown in the results of a qualitative case study conducted with 33 graduate students. The sample included 25 females and 8 males, enrolled in a teacher education program. Participants were asked about advantages and disadvantages of creating and maintaining an electronic portfolio using a WordPress blog during program orientation. This question was posed to participants after seeing 10 minutes of introductory information about electronic portfolios, including an example portfolio entry, and identifying WordPress as the platform. One student had previous experience with WordPress. Anonymous responses were collected using Poll Everywhere.com.

Data was organized using analytical coding, according to procedures described by Richards [41]. Analysis of data showed three categories. The first category, progress tracking, suggests that participants perceived electronic portfolios as a useful method for showing progress across time. Evidentiary comments for this included the following: "it is a great format for documenting and tracking growth and progress," and "the bPortfolio seems like an excellent way to document my progress over the... program." The second category, efficiency and convenience, suggests participants viewed electronic portfolios as useful for recording, organizing, and sharing program requirements, assignments, and accomplishments. Supporting comments included, "I like that it is online and easily accessible," and "It seems like a convenient method for our professors to determine whether we are completing the necessary components of our certification program." The last category, content and frequency, suggests that participants were unsure about the contents of portfolio entries and how often they would be expected to update their blog.

One point of interest is that three participants identified the portfolio as a resource to share with future employers. Four participants suggested technical skills and hardware requirements as a potential area of concern, although the majority of comments indicated enthusiasm about creating and maintaining a portfolio, with little mention of requisite computer skills.

In summary, participants perceived electronic portfolios, as a convenient method for organizing information and showing progress over time. Participants were most concerned about the content and frequency of their portfolio writing. The source of this concern likely comes from the perception that an electronic portfolio is more like an online diary, where content is inspired by the desire to publically share inner-dialogue.

Results suggest that instructors implementing electronic portfolios using a blog platform emphasize the purpose of the portfolio and specific strategies for authoring entries. In addition, significant attention should be given to training students on how to write entries that include analysis and reflection, instead of recall and description. However, enabling students to use their portfolios as an aid to learning, wherein its contents show new opinions, altered perspectives, and adoption of alternative ideas, is difficult to achieve [16] [36]. Indeed, Shepherd \& Hannafin indicate that effective portfolio use involves multiform supports, such as tutorials, prompts, and even mentoring [42]. 


\section{CONCLUSION}

Use of electronic portfolios in education is sure to increase, both for pedagogical reasons and for those dealing with assessment, accreditation, and accountability. The evolution of portfolio containers has advanced quickly, beginning with technical and hardware intensive models in the 90s, progressing to free online applications today. Researchers continue to address fundamental questions about electronic portfolios, such as their impact on achievement and influence on student development of professional knowledge and skills [16] [36] [43]. However, advances in technology have nearly outpaced models which show instructors how to integrate electronic portfolios through social media platforms. The following steps serve as a starting point for this work:

1. defining purpose and scope,

2. selecting social media platforms through experimentation and testing,

3. constructing a model,

4. instructing on appropriate use,

5. and integrating questions and prompts to elicit quality portfolio entries.

Implementation represents challenges which can be overcome with planning, experimentation, and finetuning. During implementation, instructors and administrators simultaneous identify strategies for prompting high-quality portfolio entries. Neglecting methods for assisting students as they add content to their portfolios results in portfolio populated with descriptions, opinions, and personal anecdotes, instead of reflection and self-assessment, characterized by analytical and expository writing. Although eliciting high-quality entries depends on purpose, discipline, and context, some general strategies applicable to multiple fields include

1. writing prompts in the form of questions or statements,

2. item analysis,

3. case analysis,

4. self-evaluation with supporting evidence,

5. and peer assessment.

Another consideration comes from the results of a case study, which suggests that students possess preconceptions about using social media as a repository for electronic portfolio content. Students interpreted electronic portfolios as online diaries. As a result, they expressed concern about how often they were expected to add entries, along with confusion about content. Students were quick to identify features of social media portfolios associated with efficiency, organization, and convenience. However, the connection between learning, exemplified through analytical and reflective writing, and portfolio keeping was identified as an attribute. Instructors and administrators interested in improving electronic portfolio performance would do well to address these types of beliefs during portfolio setup and training.

The information shown provides an initial outline for combining social media with electronic portfolio keeping, specifically through the use of blogs as portfolio containers. Additional lines of inquiry are inferred within this outline. For example, which social media platform is easiest to use for displaying electronic portfolio content? In what way can social media applications be combined to enhance portfolio entries? How does electronic portfolio performance correlate with other measures of professional achievement? These lines of inquiry represent new research opportunities for those interested in developing the educative potential of creating and managing electronic portfolios in social media applications. 
Implementing Electronic Portfolios Through Social Media Platforms: Steps and Student Perceptions

\section{ABOUT THE AUTHORS}

David W. Denton is an assistant professor of teacher education at Seattle Pacific University. One of his areas of interest is using instructional technology to improve student learning in traditional and online classroom settings. He can be contacted at dentod@spu.edu

David Wicks is an assistant professor of instructional technology at Seattle Pacific University. One of his areas of interest is the use of social media to collaboratively construct meaning with others. He can be contacted atdwicks@spu.edu

\section{REFERENCES}

1. Spellings, M. A Test of Leadership. United States Department of Education (2006). http://www2.ed.gov/about/bdscomm/list/hiedfuture/reports/final-report.pdf

2. Basken, P. A Year Later, Spellings Report Still Makes Ripples. Chronicle of Higher Education 54(5): (2007). http://www.csun.edu/pubrels/clips/Sept07/09-24-07M.pdf

3. Meier, D. Will Standards Save Public Education? Boston, MA: Beacon Press, 2000.

4. Urban, W. J., \& Wagoner, J. L. American Education, 4th ed.,. New York, NY: McGraw Hill, 2009.

5. Teacher Performance Assessment About the TPA (2012). http://tpafieldtest.nesinc.com/PageView.aspx?f=GEN_AbouttheTests.html

6. Lee, J., \& Reeves, T. Revisiting the Impact of NCLB High-Stakes School Accountability, Capacity, and Resources. State NAEP 1990-2009 Reading and Math Achievement Gaps and Trends. Educational Evaluation and Policy Analysis 34(2): 209-223, 2012.

7. Baker, S., Gersten, R., \& Lee, D. A Synthesis of Empirical Research on Teaching Mathematics to Low-Achieving Students. Elementary School Journal 103(1): 51-73, 2002.

8. Graham, S., \& Perin, D. A Meta-Analysis of Writing Instruction for Adolescent Students. Journal of Educational Psychology 99(3): 445-476, 2007.

9. Guthrie, J. T., Schafer, W. D., Von Secker, C., \& Alban, T. Contributions of Instructional Practices to Reading Achievement in a Statewide Improvement Program. Journal of Educational Research 93(4): 211-225, 2000.

10. Shermis, M. D. \& DiVesta, F. J. Classroom Assessment in Action. Lanham, MD: Rowan \& Littlefield, 2011.

11. Smith, S. B., Cook, C. M, Faulkner, S. A., \& Peers, M. G. Electronic and Paper-Based Teaching Portfolios: Student Perceptions and Recommendations. Paper presented at the Annual Meeting of the American Educational Research Association, Chicago, IL (April 2007).

12. Shulman, L. Teacher Portfolios: A Theoretical Activity. In N. Lyons (Ed.), With Portfolio in Hand: Validating the New Teacher Professionalism, New York, NY: Teachers College Press, 23-37, 1998.

13. Lyons, N. Introduction. In N. Lyons (Ed.), With Portfolio in Hand: Validating the New Teacher Professionalism, Teachers College Press: New York, NY, 1-8, 1998.

14. Wolf, K. The Schoolteacher's Portfolio: Issues in Design, Implementation, and Evaluation. Phi Delta Kappan, 73(2): 129-136, 1991.

15. Yao, Y., Aldrich, J., Foster, K., \& Pecina, U. Preservice Teachers' Perceptions of an Electronic Portfolio as a Tool for Reflection and Teacher Certification. Journal of Educational Research \& Policy Studies 9(1): 25-43, 2009.

16. Ayan, D., \& Seferoglu, G. Using Electronic Portfolios to Promote Reflective Thinking in Language Teacher Education. Educational Studies 37(5): 513-521, 2011.

17. Carney, J. Analyzing Research on Teachers' Electronic Portfolios: What Does It Tell Us about Portfolios and Methods for Studying Them? Journal of Computing in Teacher Education 22(3): 8997, 2006. 
18. Lumpe, A.T., Wicks, D., \& Williams, T. bPortfolios: Blog Portfolios and Self-Tagging as Reflective Practice for Teachers. Paper presented at the Sloan-C International Symposium on Emerging Technology Applications for Online Learning, San Jose, CA (July 2011).

19. Abrami, P. C., \& Barret, H. Directions for Research and Development on Electronic Portfolio. Canadian Journal of Learning and Technology 31(3): 1-15, 2005.

20. Strudler, N., \& Wetzel, K. The Diffusion of Electronic Portfolios in Teacher Education: Issues of Initiation and Implementation. Journal of Research on Technology in Education, 37(4): 411-433, 2005.

21. Gibson, D., \& Barrett, H. Directions in electronic portfolio development. Contemporary Issues in technology and Teacher Education 2(4): 559-576, 2003.

22. Waters, J. K. E-Portfolios Come of Age. T.H.E. Journal 36(10): 23-29, 2009.

23. Chuang, H. Weblog-Based Electronic Portfolios for Student Teachers in Taiwan. Educational Technology Research and Development 58(2): 211-227, 2010.

24. Banister, S., Vannatta, R. A., \& Ross, C. Testing Electronic Portfolio Systems in Teacher Education: Finding the Right Fit. Action in Teacher Education 27(4): 81-90, 2006.

25. Klages, M. A., \& Clark, J. New Worlds of Errors and Expectations: Basic Writers and Digital Assumptions. Journal of Basic Writing 28(1): 32-49, 2009.

26. Hsu, H., \& Wang, S. The Impact of Using Blogs on College Students' Reading Comprehension and Learning Motivation. Literacy Research and Instruction 50(1): 68-88, 2011.

27. Bonk, C. J., \& Zhang, K. Introducing the R2D2 Model: Online Learning for the Diverse Learners of this World. Distance Education 27(2): 249-264, 2006.

28. Sawmiller, A. Classroom Blogging: What is the Role in Science Learning? Clearing House: $A$ Journal of Educational Strategies, Issues and Ideas 83(2): 44-48, 2010.

29. Family Educational Rights and Privacy Act FERPA General Guidelines for Students (2011). http://www2.ed.gov/policy/gen/guid/fpco/ferpa/students.html

30. Kim, P., Ng, C., \& Lim, G. When Cloud Computing Meets with Semantic Web: A New Design for E-Portfolio Systems in the Social Media Era. British Journal of Educational Technology 41(6): 1018-1028, 2010.

31. Barrett, H. C. Balancing the Two Faces of E-portfolios. In S. Hirtz \& K. Kelly (Eds.), Digital World: Advice, Guidelines, and Effective Practice from Around the Globe, British Columbia, Canada: Commonwealth of Learning (2): 291-310, 2011.

32. Barrett, H. C., \& Knezek, D. E-Portfolios: Issues in Assessment and Preservice Teacher Preparation. Paper presented at the Annual Conference of the American Educational Research Association, Chicago, IL (April 2003). http://electronicportfolios.com/portfolios/ AERA2003.pdf

33. Wilhelm, L., Puckett, K., Beisser, S., Wishart, W., Merideth, E., \& Sivakumaran, T. Lessons Learned from the Implementation of Electronic Portfolios at Three Universities. Techtrends 50(4): 62-71, 2006.

34. International Society for Technology in Education Digital citizenship (2011). http://www.iste.org/standards/nets-for-students.aspx

35. Denton, D. W. Improving the Quality of Preservice Teachers' Evidence-Based Writing Entries in Electronic Portfolios. Manuscript accepted for publication. International Journal of ePortfolio, 2012.

36. Yao, Y., Thomas, M., Nickens, N., Downing, J., Burkett, R. S., \& Lamson, S. Validity

37. Evidence of an Electronic Portfolio for Preservice Teachers. Educational Measurement: Issues and Practice 27(1): 10-24, 2008.

38. Griffith, B., \& Frieden, G. Facilitating Reflective Thinking in Counselor Education. Counselor Education and Supervision 40(2): 82-93, 2000.

39. Reid, R., \& Lienemann, T. Strategy Instruction for Students with Learning Disabilities. New York, NY: Guilford, 2006.

40. Couros, A. V. Examining the Open Movement: Possibilities and Implications for 41. Education. University of Regina, Canada: ProQuest Digital database, 2011. 
42. United States Department of Education. Transforming American Education: Learning Powered by Technology. U.S. Department of Education, Office of Educational Technology, 2010. http://www.ed.gov/technology/netp-2010

43. Richards, L. Handling Qualitative Data. Thousand Oaks, CA: Sage, 2005.

44. Shepherd, C., \& Hannafin, M. Supporting Preservice Teacher Inquiry with Electronic Portfolios. Journal of Technology and Teacher Education 19(2): 189-207, 2011.

45. McIntyre, C., \& Dangel, J. Teacher Candidate Portfolios: Routine or Reflective Action? Action in Teacher Education 31(2): 74-85, 2009. 